\title{
TEORES DE LIGNINA E ÁCIDOS URÔNICOS NA MADEIRA E POLPA CELULÓSICA DE EUCALIPTO ${ }^{1}$
}

\author{
Antônio José Vinha Zanuncio² e Jorge Luiz Colodette²
}

\begin{abstract}
RESUMO - O teor de lignina influencia a alvura da polpa celulósica e, por isto, é uma variável importante no processo de sua fabricação, o que torna fundamental estabelecer métodos para determinar seu valor. Baseado na hipótese de que os métodos disponíveis para avaliar o teor de lignina solúvel medem, também, os ácidos urônicos na madeira, isto tornaria este método impreciso. O objetivo desse trabalho foi verificar se existe correlação entre a lignina e ácidos urônicos na madeira de eucalipto e na polpa celulósica. Quarenta e seis amostras, sendo 24 amostras de madeira, 11 de polpa não branqueada e 11 de polpa branqueada foram utilizadas para se determinar os teores de lignina e de ácidos urônicos. As amostras de madeira apresentaram maior quantidade de lignina e, por isto, os teores de ácidos urônicos não influenciaram de forma significativa os valores da mesma. Amostras de polpa celulósica, com menor quantidade de lignina, mostraram grande correlação entre os valores de ácidos urônicos e lignina. Os testes de medição de lignina na polpa celulósica apresentaram baixa precisão.

Palavras-chave: Ácidos urônicos, Madeira de eucalipto e Lignina.
\end{abstract}

\section{CORRELATION BETWEEN LEVELS OF LIGNIN AND URONIC ACIDS IN THE WOOD AND CELULOSE PULP OF EUCALYPTUS}

\begin{abstract}
The lignin content influences the cellulosic pulp brightness and therefore is an important variable in the manufacturing process, making it essential to establish methods to determine its value. Based on the assumption that the available methods for assessing the soluble lignin content measure also the uronic acids in the wood. which would make this method inaccurate. This study aimed to determine whether a correlation exists between the lignin and uronic acids in the eucalypt wood and in the cellulosic pulp. Twenty-four wood samples, being eleven unbleached pulp and eleven bleached were used to determine the lignin content and uronic acids. The wood samples showed a higher amount of lignin and, therefore, the levels of uronic acid did not influence significantly the wood values. Cellulosic pulp samples with less lignin showed high correlation among the uronic acids amounts and lignin. Tests for the lignin measurement in the cellulosic pulp showed low accuracy.
\end{abstract}

Keywords: Uronic acids, Eucalyptus wood and Lignin.

\section{INTRODUÇÃO}

O setor de celulose e papel tem-se expandido de forma acentuada, com produções, em 2007, de aproximadamente 11,9 milhões e 9,0 milhões de toneladas e crescimentos de $6,6 \%$ no setor de celulose e $2,8 \%$ no de papel, respectivamente. O valor alcançado pelas exportações também se destacou, com US\$ 4,7 bilhões, evidenciando aumento de 16,1\% em relação a 2006 e saldo comercial de US\$3,8 bilhões, além da geração de R\$ 2,1 bilhões em impostos (BRACELPA, 2008).
A lignina foi descoberta em 1938 por Anselme Payen após submeter a madeira a tratamento químico com ácido sulfúrico concentrado. Sessenta e um anos depois, Peter Klason lançou a ideia de que a lignina estaria relacionada com o álcool coniferílico e, posteriormente, que eram unidos por ligação éter. Após a celulose, a lignina é a substância orgânica com maior frequência nos tecidos vegetais, com grande quantidade de carbonos aromáticos. A concentração de lignina varia de 28 a 36\% em coníferas (FENGEL e WEGENER, 1989) e de 26,0 a 34,2\% em folhosas da Amazônia (SANTANA

\footnotetext{
${ }^{1}$ Recebido em 27.07.2009 e aceito para publicação em 16.12.2010.

${ }^{2}$ Universidade Federal de Viçosa, UFV, Brasil. E-mail: <ajvzanuncio@yahoo.com.br> e <colodett@ufv.br>.
}

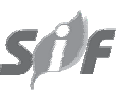

Revista Árvore, Viçosa-MG, v.35, n.2, p.341-347, 2011 
e OKINO, 2007). Formam um composto de natureza aromática e tridimensional (TRUGILHO et al., 1996), têm elevada massa molar e, como base estrutural, três tipos de álcoois que possuem unidades de fenilpropano ligadas a grupos metoxílicos e hidroxílicos, dependendo do tipo de madeira. As unidades de fenilpropano são unidas por dois tipos de ligações: ligação éter (C-O-C), que são mais fracas; e ligações carbono-carbono (C-C), que são mais fortes (SJOSTROM et al., 1993). A primeira representa 2/3 ou mais das ligações da lignina (PILÓVELOSO et al., 1993), como mostrado na Figura 1.

As ligninas são estruturas complexas e abundantes, com aproximadamente $30 \%$ do carbono da biosfera (FENGEL e WEGENER, 1989), presentes na maioria das plantas, mas com estrutura básica diferente entre espécies vegetais. São encontradas, principalmente, na lamela média e, em menores proporções, na parede secundária e nos traqueídeos, com funções como aumento da rigidez da parede celular, agente cimentante entre uma célula e outra, redução da permeabilidade da parede celular à água, proteção da madeira contra microrganismos e aumento da resistência da planta à compressão para permitir o seu crescimento (D’ALMEIDA et al., 1988; WILLFÖR et al., 2002).

O corte transversal da parede secundária de uma célula tipicamente lignificada (Figura 2) mostra que é à prova de água, bloqueando a difusão desta e de

Fonte: PILÓ-VELOSO et al. (1993).

Source: (Piló-Veloso et al. (1993).

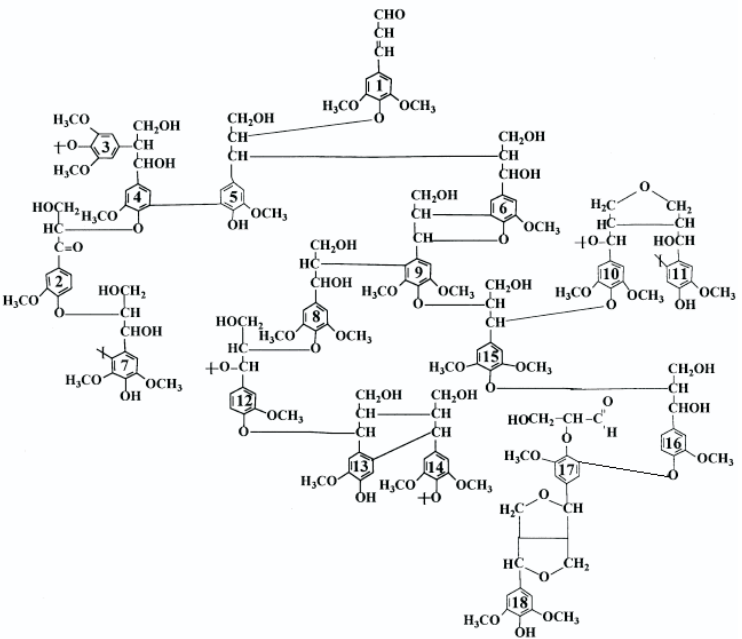

Figura 1-Estrutura proposta para a macromolécula de lignina de Eucalyptus grandis.

Figure 1-Proposed structure for the lignin macromolecule of Eucalyptus grandis.

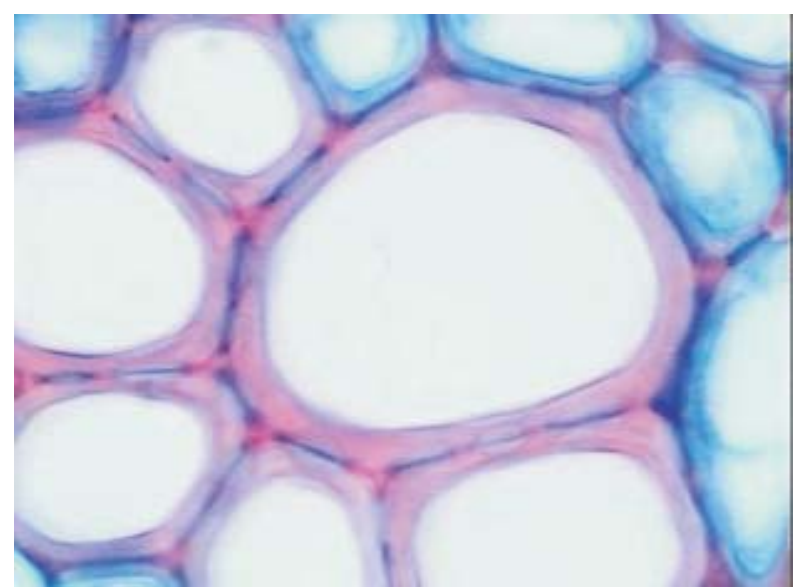

Figura 2 - Corte transversal do xilema, com parede celular lignificada na parte corada de rosa.

Figure 2-Xylem transversal cut with the lignified cellular wall in pinkish color.

nutrientes dissolvidos para dentro da célula. Essa é uma das razões para explicar a morte de células com paredes lignificadas na maturidade (KLOCK et al., 2005).

Os grupos funcionais metoxílicos (OCH3) característicos da lignina e com aproximadamente 90\% da ocorrência na natureza em moléculas de lignina de coníferas; o hidroxílico (fenólico), que representa cerca de $10 \%$ do peso da lignina de coníferas e folhosas; e os grupos carboxílicos ( $\mathrm{COOH})$ e carbonilas (CO) representam outra característica importante da lignina.

A presença de altos teores de substâncias de natureza aromática como extrativos e lignina dá como consequência carvão com maior densidade e melhores propriedades físicomecânicas. Madeiras com maiores teores de lignina resultam em carvão com melhor poder calorífico (SATANOKA et al., 1963). Entretanto, no processo de produção da polpa celulósica alto teor de lignina implica maior gasto de reagentes, o que faz que seja indesejável para esse fim (GOMIDE, 2006).

Os perácidos são consumidos em reações de oxidação da lignina por decomposição espontânea e catalisadas por metais de transição durante o branqueamento (BRASILEIRO et al., 2001).

Os ácidos urônicos estão presentes em algumas hemiceluloses, principalmente nas xilanas, como ácido 4-0-metilglicourônico (MeGlcAs) e se modificam em sua estrutura, transformando-se em ácidos hexenurônicos durante o processo de polpação. Esses ácidos são indesejáveis no processo de branqueamento por 
consumirem reagentes como cloro, dióxido de cloro, ozônio ou perácidos, usados no branqueamento e contabilizados no número Kappa das polpas kraft com afinidade por metais de transição ( $\mathrm{Mn}, \mathrm{Cu}, \mathrm{Fe}$, Co etc.), também indesejáveis na polpa. A quantidade de ácidos hexenurônicos na polpa depende da madeira e das condições de polpação. Uma etapa de hidrólise ácida é usada antes do branqueamento para minimizar os efeitos dos ácidos hexenurônicos quando são convertidos em ácido 2-furanocarboxílico, ácido fórmico e 5-carboxi-2-furaldeído e removidos para não interferirem na qualidade da polpa celulósica (COSTA et al., 2000).

O crescimento do setor de celulose e papel torna necessária alta qualidade da matéria-prima com controle da cadeia produtiva. A avaliação do teor de lignina é um teste importante e que influencia na carga de reagentes na produção da polpa e, por isso, é fundamental que tal procedimento tenha alta precisão.

O método tradicional de medição de lignina insolúvel proposto por Klason no início do século passado é relativamente preciso para medições dos teores de lignina de madeiras de coníferas, pois estas apresentam quantidades irrisórias da chamada lignina solúvel em ácido. Em se tratando de madeiras de folhosas, principalmente de eucalipto, o método de Klason não é inteiramente aplicável sozinho, já que a fração significativa da lignina dessas madeiras é solúvel em ácido, fazendo que esse método subestime os verdadeiros conteúdos de lignina. Para evitar esse erro, a medição da lignina de madeira de folhosas utiliza um método complementar ao de Klason, que inclui também a análise da lignina solúvel. O método de medição da lignina solúvel é baseado em colorimetria e foi bem descrito por Goldschmid (1971). Esse método se baseia em medições de absorbâncias da amostra de lignina solúvel nos comprimentos de ondas de 215 e 280 nm e, através de cálculos matemáticos, deriva-se o teor de lignina na solução.

Os resultados experimentais de lignina solúvel de madeiras de eucalipto (GOLDSCHMID, 1971) são muito elevados (3,5-5,5\%), e existe a possibilidade de estarem sendo também medidos outros compostos que absorvem luz na região do ultravioleta, particularmente na faixa de 200-300 nm. Os compostos que podem absorver luz nessa faixa incluem os chamados ácidos urôncios e seus derivados. Após hidrólise ácida intempestiva da madeira com ácido forte, conforme previsto no método de Klason, não é improvável que muitos dos ácidos urônicos originalmente presentes na madeira se tornem solúvel em ácido e terminem exatamente no filtrado, onde se mede a chamada lignina solúvel. Portanto, há a possibilidade de que haja algum erro sobre a estimação da lignina solúvel, pois a técnica pode estar quantificando alguma fração de ácidos urônicos como se fossem lignina solúvel.

Baseado na hipótese de que o método de medição da lignina solúvel pode também medir certa quantidade de ácidos urônicos, o objetivo deste trabalho foi verificar se há correlação entre esses dois valores, a fim de verificar a precisão dos métodos disponíveis.

\section{MATERIAL E MÉTODOS}

\subsection{Material}

As amostras de madeira foram provenientes de seis clones de Eucalyptus (Eucalyptus grandis $\mathrm{x}$ Eucalyptus urophylla de plantios comerciais com 3 anos de idade, com espaçamento de 3,0 x 3,0 m nas regiões de Guanhães, Cocais, Santa Bárbara e Rio Doce, em Minas Gerais.

O método de seleção das amostras foi baseado em amostras compostas por cavacos de cinco árvores por amostra. Os cavacos foram deixados por $48 \mathrm{~h} \mathrm{em}$ sala climatizada a $25^{\circ} \mathrm{C}$ e $50 \%$ de umidade relativa e, a seguir, transformados em serragem em moinho Wiley. Posteriormente, as serragens foram classificadas em peneiras de 40 e 60 mesh e reconduzidas para a sala climatizada, onde permaneceram por $24 \mathrm{~h}$.

As amostras de polpas branqueadas e não branqueadas foram obtidas do Laboratório de Celulose e Papel da Universidade Federal de Viçosa (UFV), em Viçosa, MG.

\subsection{Determinação do teor absolutamente seco (a.s.)}

A massa das amostras de madeira utilizada para as próximas análises devem ser totalmente secas, e com isso é preciso calcular o seu teor de umidade. O primeiro procedimento foi aquecer o pesa-filtro destampado por $5 \mathrm{~h}$ a $105^{\circ} \mathrm{C}$, tampado, colocado em dessecador por 30 min e pesado em balança com precisão de $0,001 \mathrm{~g}(\mathrm{~A})$.

O segundo procedimento consistiu em pesar as amostras de serragem. A balança foi zerada com o pesafiltro e, após a pesagem de cada amostra, a massa foi

Revista Árvore, Viçosa-MG, v.35, n.2, p.341-347, 2011 
obtida e anotada (B). O pesa-filtro foi colocado novamente em estufa a $105^{\circ} \mathrm{C}$ por $5 \mathrm{~h}$. As amostras foram deixadas no dessecador por 30 min, e após esse tempo o material foi pesado com a mesma precisão anterior e anotada a nova massa (C)

$$
\mathrm{U}(\%)=((\mathrm{C}-\mathrm{A}) / \mathrm{B}) \times 100 .
$$

\subsection{Preparação de amostras livres de extrativos}

Os extrativos foram retirados das amostras de serragem para continuar as análises e alcançar os objetivos com maior precisão. As amostras foram pesadas com 2 g a.s., colocadas em cadinho com um balão de $150 \mathrm{~mL}$ com acetona e um funil condensador. Esse conjunto foi posto por 4 h em bateria de extração. Após esse procedimento, as amostras foram colocadas na capela para evaporação do excesso de acetona e, por fim, deixadas na sala climatizada por $24 \mathrm{~h}$.

O teor de a.s. no próximo procedimento foi determinado com a metodologia descrita no item 2.2.

\subsection{Hidrólise ácida}

Em balança com precisão de 0,1 mg foram pesados $300 \mathrm{mg}$ de serragem acondicionados em tubos de ensaio (60 mm de comprimento e 7,5 mm de diâmetro) e colocados em banho-maria a $30^{\circ} \mathrm{C}$, para a hidrólise ácida. Três ml de $\mathrm{H} 2 \mathrm{SO} 4$ a $72 \%$ foram adicionados com o auxílio de uma pipeta, deixando-se em descanso por $1 \mathrm{~h}$. Nesse período, os tubos foram mexidos, a cada três min, com bastão de vidro. A seguir, a mistura com $84 \mathrm{~mL}$ de água deionizada foi colocada em frasco tipo "penicilina" de $100 \mathrm{~mL}$, fechado hermeticamente e levado à autoclave por $1 \mathrm{~h}$ a partir do momento da ebulição. As amostras foram filtradas em membrana éster e a solução, completada com água deionizada para $250 \mathrm{~mL}$ ao término desse período. Uma panela de pressão de 6 L, com 12 amostras por vez, foi utilizada nesse experimento.

\subsection{Avaliação dos ácidos urônicos}

Uma amostra de 0,3 mL da hidrólise ácida foi pipetada e colocada em um tubo de ensaio com $0,3 \mathrm{~mL}$ de uma solução de ( $\mathrm{NaCl}+\mathrm{H} 3 \mathrm{BO} 3)$ e agitada por 10 seg para medição dos ácidos urônicos. Após esse período, $5 \mathrm{~mL}$ de H2SO4 concentrado foram acrescentados e a solução agitada por mais $10 \mathrm{seg}$. Esses tubos foram colocados em banho-maria a $70^{\circ} \mathrm{C}$ por 40 min e resfriados por 2 min em água corrente. Finalmente, 0,2 mL de dimetilfenol foi adicionado, agitando-se por 5 seg no vórtex e depois por mais $15 \mathrm{seg}$. Após $10 \mathrm{~min}$, foi obtido o teor de ácidos urônicos por meio dos valores de absorbância no espectrofotômetro Varian Cary 50 Probe para os comprimentos de onda de $450 \mathrm{~nm}$ e $400 \mathrm{~nm}$, seguindo-se a equação: teor de ácidos urônicos (\%) = $(15,37 *$ (absorbância $450 \mathrm{~nm})-$ absorbância 400 nm+ 0,052)

A água deionizada foi utilizada no controle.

\subsection{Medição da lignina solúvel}

Foram utilizados $25 \mathrm{~mL}$ da amostra da hidrólise, completados para $100 \mathrm{~mL}$ para medição, no espectrofotômetro Varian cary 50 probe com comprimento de onda de $215 \mathrm{~nm}$ e $280 \mathrm{~nm}$, do teor de lignina solúvel $(\%)=((4,538$ *absorbância $(215$ nm) $)$ absorbância(280))*1,11.

Uma solução de 3 mL de H2SO4 a 72\%, diluída em um balão de $1 \mathrm{~L}$, foi utilizada no controle.

\subsection{Montagem do experimento}

Os testes foram realizados em duas etapas. $\mathrm{Na}$ primeira, os teores de lignina e de ácidos urônicos foram determinados nas 24 amostras de madeira de eucalipto e na segunda, em 11 amostras de polpas celulósicas branqueadas e não branqueadas.

\section{RESULTADOS E DISCUSSÃO}

Os teores de lignina solúvel e de ácidos urônicos variaram entre os clones de eucalipto e nas regiões de Guanhães, Cocais, Santa Bárbara e Rio Doce e Ipaba, Minas Gerais.

O teste de correlação entre os valores de lignina e de ácidos urônicos, em todas as regiões, mostrou valores de $r=0,243185$ e $r^{2}=0,0591389$, ou seja, a quantidade de ácidos urônicos explica, apenas, 5,9\% daquela lignina (Tabela 1 e Figura 3).

Os teores de lignina solúvel e de ácidos urônicos nas amostras de madeira de eucalipto variaram, respectivamente, de $2,95 \%$ a $4,30 \%$ e de $4,05 \%$ a $5,29 \%$, superiores aos relatados para folhosas da região amazônica, de 0,7\% a 1,8\% e de 1,5\% a 3,1\% (SANTANA; OKINO, 2007). No entanto, amostras de clones de eucalipto de diversas espécies mostraram teores de lignina entre 3,1\% e 5,1\% e de ácidos urônicos de 4,7\% e 3,2\%, semelhantes aos observados neste trabalho (GOMIDE et al., 2005). 
Tabela 1 - Porcentagem de lignina e de ácidos urônicos extraídos de amostras de clones de eucalipto das regiões de Guanhães, Cocais, Santa Bárbara e Rio Doce e Ipaba, Minas Gerais.

Table 1- Lignin and uronic acids percentage extracted from the eucalypt clones samples from the regions of Guanhães, Cocais, Santa Bárbara, Rio Doce, and Ipaba, Minas Gerais State, Brazil .

\begin{tabular}{|c|c|c|c|c|c|}
\hline Clones & $\begin{array}{c}\text { Lignina Solúvel (\%) } \\
\text { Guanhães }\end{array}$ & Ácidos Urônicos (\%) & Clones & $\begin{array}{c}\text { Lignina Solúvel (\%) } \\
\text { Cocais }\end{array}$ & $\begin{array}{c}\text { Ácidos Urônicos } \\
(\%)\end{array}$ \\
\hline 1213 & 4,29 & 5,18 & 1213 & 3,63 & 5,17 \\
\hline 1215 & 4,19 & 5,01 & 1274 & 3,49 & 5,06 \\
\hline 57 & 3,86 & 4,71 & 1215 & 3,42 & 5,21 \\
\hline 1046 & 3,62 & 4,19 & 1046 & 3,31 & 4,82 \\
\hline 7074 & 3,60 & 4,62 & 7074 & 3,27 & 5,10 \\
\hline 1274 & 3,39 & 4,49 & 57 & 3,25 & 5,38 \\
\hline & Santa Bárbara & & & Rio Doce e Ipaba & \\
\hline 1213 & 4,13 & 5,27 & 7074 & 3,77 & 4,60 \\
\hline 7074 & 3,65 & 4,60 & 1213 & 3,44 & 4,34 \\
\hline 57 & 3,34 & 4,83 & 1274 & 3,32 & 4,81 \\
\hline 1274 & 3,29 & 4,36 & 1046 & 3,32 & 4,05 \\
\hline 1046 & 3,24 & 4,22 & 1215 & 3,15 & 4,50 \\
\hline 1215 & 3,15 & 4,35 & 57 & 2,95 & 5,28 \\
\hline
\end{tabular}

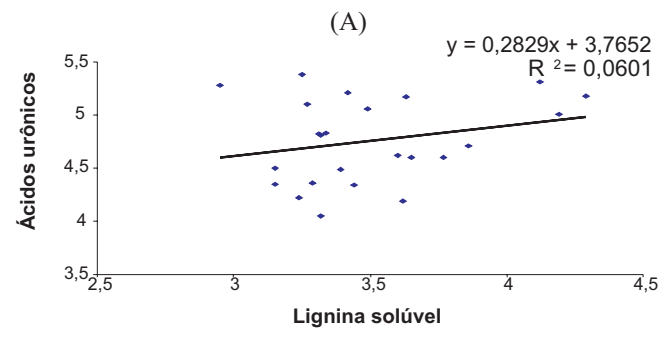

(B)

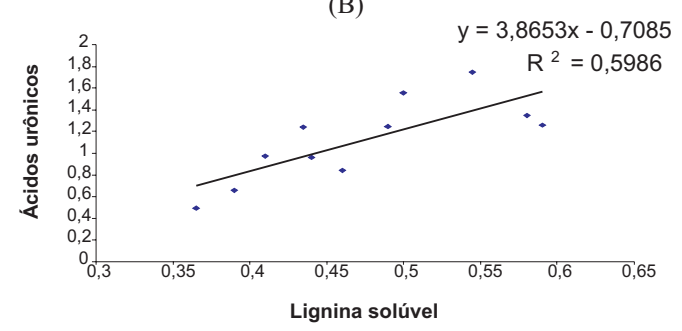

(C)

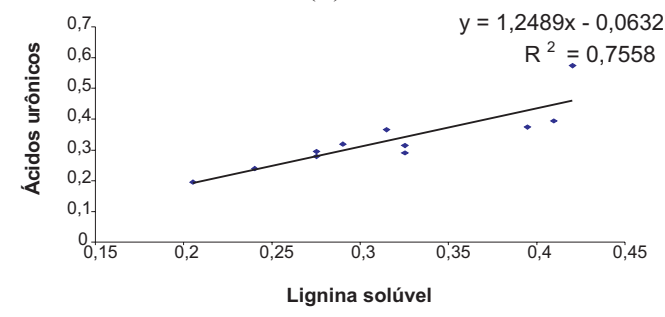

Figura 3 - Gráfico de correlação entre lignina solúvel e ácidos urônicos na madeira (A), na polpa não branqueada(B) e na polpa branqueada(C).

Figure 3-Graphic with the correlations between soluble lignin and uronic acids in the wood (A), in the non-bleached pulp (B), and in the bleached (C) pulp.
Os clones 1215 e 1046 de Santa Bárbara e 1215 e 57 de Rio Doce e Ipaba podem ser considerados de baixa densidade, pois tiveram teores de lignina próximos dos 3,0\%, enquanto a média dos clones de alta densidade foi de 3,5\% (QUEIROZ et al., 2004).

O teste de correlação entre os valores de lignina e de ácidos urônicos para polpa não branqueada mostrou valores de $r=0,7737703421$ e $r^{2}=0,598717$, ou seja, alteração nos valores de lignina influenciou 59,87\% daqueles de ácidos urônicos. Esses valores, para polpa branqueada, mostraram $r=0,869367$ e $r^{2}=0,755799$, indicando que alteração nos valores de lignina influenciou 75,57\% daqueles dos ácidos urônicos (Tabela 2 e Figura 3).

A quantidade de ácidos urônicos afeta a qualidade dos métodos de medição de lignina. Os métodos de medição de lignina não são altamente precisos, mostrando ser necessário estudar parâmetros que afetem a precisão deles, como verificado nas 36 espécies de madeira tropical da Amazônia, quando o ácido urônico afetou a medição de lignina (SANTANA; OKINO, 2007). A avaliação do teor de lignina pelos métodos de lignina em detergente ácido (LDA), lignina Klason (LK) e lignina permanganato de potássio (LPer) mostrou valores diferentes para amostras semelhantes (FUZZETO, 2003).

Na madeira, o valor de ácidos urônicos foi relativamente baixo em relação ao da lignina. Por isso, o primeiro parâmetro não deve influenciar o teor do último. Na polpa celulósica, de onde grande parte da lignina foi retirada, o teor de ácidos hexenurônicos 
Tabela 2 - Teor de lignina e de ácidos urônicos extraídos de amostras de polpa não branqueada e branqueada. Table 2 - Lignin and uronic acids levels extracted from the non-bleached (B) and bleached (C) pulp samples.

\begin{tabular}{|c|c|c|c|c|c|}
\hline \multicolumn{3}{|c|}{ Polpa não branqueada } & \multicolumn{3}{|c|}{ Polpa branqueada } \\
\hline $\begin{array}{l}\text { Identificação } \\
\text { da Polpa }\end{array}$ & Lignina solúvel & Ácidos urônicos & $\begin{array}{c}\text { Identificação } \\
\text { da Polpa }\end{array}$ & Lignina solúvel & Ácidos urônicos \\
\hline $14 \mathrm{M}$ & 0,590 & 1,260 & $2 \mathrm{M}$ & 0,420 & 0,575 \\
\hline $13 \mathrm{M}$ & 0,580 & 1,345 & $6 \mathrm{M}$ & 0,410 & 0,395 \\
\hline $2 \mathrm{M}$ & 0,545 & 1,745 & $10 \mathrm{M}$ & 0,395 & 0,375 \\
\hline $6 \mathrm{M}$ & 0,500 & 1,560 & $8 \mathrm{M}$ & 0,325 & 0,290 \\
\hline $10 \mathrm{M}$ & 0,490 & 1,245 & $15 \mathrm{M}$ & 0,325 & 0,315 \\
\hline $15 \mathrm{M}$ & 0,460 & 0,840 & $14 \mathrm{M}$ & 0,315 & 0,365 \\
\hline $11 \mathrm{M}$ & 0,440 & 0,960 & $13 \mathrm{M}$ & 0,290 & 0,320 \\
\hline $4 \mathrm{M}$ & 0,435 & 1,240 & $4 \mathrm{M}$ & 0,275 & 0,295 \\
\hline $8 \mathrm{M}$ & 0,410 & 0,975 & $16 \mathrm{M}$ & 0,275 & 0,280 \\
\hline $12 \mathrm{M}$ & 0,390 & 0,660 & $12 \mathrm{M}$ & 0,240 & 0,240 \\
\hline $16 \mathrm{M}$ & 0,365 & 0,495 & $11 \mathrm{M}$ & 0,205 & 0,195 \\
\hline
\end{tabular}

afetou sua medição, e isso foi confirmado na polpa branqueada, que possui menos lignina e apresentou maior correlação entre os dois valores.

\section{CONCLUSÕES}

Os valores de ácidos urônicos não alteraram os de lignina nas amostras de madeira. No entanto, amostras de polpa celulósica, com menor quantidade de lignina, tiveram grande correlação entre os de lignina e de ácidos urônicos, mostrando que os valores dos ácidos urônicos afetam os da lignina.

\section{AGRADECIMENTOS}

Ao CNPq e à UFVcred, pelo apoio financeiro.

\section{REFERÊNCIAS}

BRACELPA, http://www.bracelpa.org.br/bra/ estatisticas/pdf/booklet/Desempenho Julho2008. pdf,2008.

BRASILEIRO, L. B.; COLODETTE, J. L; PILÓVELOSO, D. A utilização de perácidos na deslignificação e no branqueamento de polpas celulósicas. Quimica Nova, v.24, n.6, p.819-829, 2001.

COSTA, M. M. et al. Branqueamento ECF de baixo investimento para a produção de um milhão ADT/ano na CENIBRA. Laboratório de Celulose e Papel. Viçosa, MG: Universidade Federal de Viçosa, 2000.

Revista Árvore, Viçosa-MG, v.35, n.2, p.341-347, 2011
D’ALMEIDA, M.L.O. Composição química dos materiais lignocelulósicos. In: D’ALMEIDA, M.L.O. Celulose e papel: tecnologia de fabricação da pasta celulósica. 2.ed., São Paulo: IPT, 1988. v.1. p.45-106.

FENGEL, D. E.; WEGENER, G. Wood chemistry, ultrastructure, reactions. Berlin: Water de Gruyter, 1989. 613p.

FUZZETO, A. P. Determinação do teor de lignina em amostras vegetais através de três métodos analíticos e correlação com digestibilidade in vitro. 2003. $73 \mathrm{f}$. Dissertação (Mestrado em Nutrição Animal) Universidade de São Paulo, São Paulo, 2003.

GOMIDE, J.L. Tecnologia e Química da Produção de Celulose. Viçosa-MG. Laboratório de Celulose e Papel, Universidade Federal de Viçosa. 2006. 235p.

GOMIDE, J. L. et al. Caracterização tecnológica para produção de celulose da nova geração de clones de Eucalyptus do Brasil. Revista Árvore, v.29, n.1, p.129-137, 2005.

GOLDSCHMID, O. Ultraviolet spectra. In: SARKANEN, K.V.; LUDWIG, C.H. (Eds.) Lignins: Occurrence, formation, structure and reactions. New York: WileyInterscience, 1971. p.241-266.

KLOCK, U. et al. Química da madeira. 3ed. Curitiba: 2005. 86p. Apostila. 
PILÓ-VELOSO, D.; NASCIMENTO, E. A.; MORAIS, S. A. L. Isolamento e análise estrutural de ligninas. Química Nova, v.16, n.5, p.435-448, 1993.

QUEIROZ, S. C. S. et al. Influência da densidade básica na qualidade da polpa Kraft de clones híbridos de Eucalyptus grandis W. Hill ex Maiden $\mathrm{x}$ Eucalyptus urophylla S.T. Blake. Revista Árvore, v.28, n.6,p.901-909, 2004.

SANTANA, M. A. E.; OKINO, E. Y. A. Chemical composition of 36 Brazilian Amazon forest wood species. Holzforschung, v.61, n.5, p.469-477, 2007.

SATANOKA, S. - TITULO DO ARTIGO. Hokkaido Daigaku, Enshurin Hokuku, v.22, n.2, p.609-814, 1963.
SJÖSTRÖM, E. Wood chemistry:

fundamentals and applications. 2.ed. New York: Academic Press, 1993. 293p.

TRUGILHO, P. F.; LIMA, J. T.; MENDES, L. M. Influência das idades nas características físicoquímicas e anatômicas da madeira de Eucalyptus saligna. Revista Cerne, v.2, n.1, p.94-11, 1996.

WILFÖR, S. M.; SMEDS, A. I.; HOLMBOMA, B. R. Chromatographic analysis of lignans. Journal of Chromatography A, v.1112, p.64-77, 2006. Disponível em: < http:/ /www.sciencedirect.com $>$. Acesso em: 14 out. 2008 
